$1-2015$

Neural Attention and Evaluative Responses to Gay and Lesbian Couples

Cheryl L. Dickter

Catherine A. Forestell

Blakely E. Mulder

Follow this and additional works at: https://scholarworks.wm.edu/aspubs

Part of the Psychology Commons 


\title{
Neural attention and evaluative responses to gay and lesbian couples
}

\author{
Cheryl L. Dickter, Catherine A. Forestell, and Blakely E. Mulder

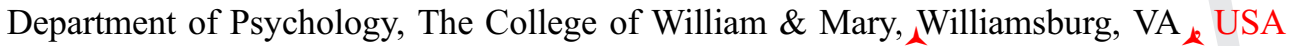

\begin{abstract}
The goal of the current study was to examine whether differential neural attentional capture and evaluative responses for out=groun (120) hosexual relative to in=group heterosexual targets occur during social categorization. To this end, 36 heterosexual participants were presented with pictures of heterosexual and homosexual couples in a picture-viewing task that was designed to assess implicit levels of discomfort toward homosexuality and explicit evaluations of pleasantness toward the images. Neural activity in the form of EEG was recorded during the presentation of the pictures, and event-related potentials resulting from these stimuli were examined. Participants also completed questionnaires that assessed the degree to which they socialized with gays and lesbians. Results demonstrated that relative to straight couples, larger P2 amplitude was observed gay but not lesbian couples. However, both gay and lesbian couples yielded a larger late positive potential than straight couples. Moreover, the degree to which participants differentially directed early neural attention to out-group lesbian versus in-group straight couples was related to their familiarity with homosexual individuals. This work, which provides an initial understanding of the neural underpinnings of attention toward homosexual couples, suggests that differences in the processing of sexual orientation can occur as early as $200 \mathrm{~ms}$ and may be moderated by familiarity.
\end{abstract}

Keywords: Event-related potentials; Sexual orientation; Social contact; Attentional capture; Couples.

In the last two decades, evaluations of sexual minorities

20 have become more positive (Steffens \& Wagner, 2004), with increasing opposition to discrimination on the basis of sexual orientation (e.g., Sherrill \& Yang, 2000; Yang, 1997). While on one hand these trends may represent a meaningful shift in public attitudes, on the other they may represent tendencies to respond in a socially desirable manner. Heated political debates continue to arise over issues such as gay marriage, with many Americans still holding negative views about legalizing marriage between same-sex couples. 30 Historically, similar discrepancies between increasingly tolerant self-reported attitudes and ongoing disparities in people's daily experiences have been observed for issues affecting people of color and women. These differences may stem from participants' 35 unwillingness to report their true attitudes because of their sensitivity to societal norms of equality (Dovidio \& Gaertner, 2000; McConahay, 1986).

Because of problems with relying on self-reported measures of attitudes, studies of the perception of social groups have moved toward using implicit measures such as the Implicit Association Test (Greenwald, McGhee, \& Schwartz, 1998) to investigate attitudes toward gays and lesbians. Studies have demonstrated that heterosexual participants generally hold more negative implicit attitudes toward homosexuals than heterosexuals when social groups are labeled (i.e., "heterosexual", "homosexual", or "gay males/lesbians") and when pictures of gay and straight couples are used (Banse, Seise, \& Zerbes, 2001; Dasgupta \& Rivera, 2006; Gabriel, Banse, \& Hug, 2007; Inbar, Pizarro, Knobe, \& Bloom, 2009; Rowatt et al., 2006).

Correspondence should be addressed to: Cheryl L. Dickter, Ph.D., Department of Psychology, The College of William \& Mary, P.O. Box 8795, Williamsburg, VA 23187, USA. E-mail: cldickter@wm.edu 
Implicit prejudices and stereotypes are the result of social categorization, which occurs when people are thought of as members of a particular social group rather than as individuals (Macrae, Milne, \& Bodenhausen, 1994). Research examining social categorization has focused mainly on race, demonstrating that racial categorization often occurs within a few hundred millise60 conds $\_$(e.g., Dickter \& Bartholow, 2007; Giner-Sorolla, García, \& Bargh, 1999; Ito \& Urland, 2003, 2005) of viewing a face. Because social categorization automatically activates learned stereotypes and implicit associations, it may lead perceivers to ascribe stereotypic traits to social group members (Brewer, 1988; Darley \& Gross, 1983; Fiske \& Neuberg, 1990) that can result in discriminatory behavior, especially toward those who are viewed to be different from the perceiver (Bargh, Chen, \& Burrows, 1996; Correll, Park, Judd, \&

70 Wittenbrink, 2002; Jussim, Palumbo, Smith, \& Madon, 2000; Payne, 2001).

In addition, researchers have investigated the extent to which rapidly, unfolding, attention-related processes might differ as a function of social categorization. Investigating early attention to social categories is important, as differential attention to in-group versus out-group members may lead to differences in later processing and person perception (e.g., Bettencourt, Dill, Greathouse, Charlton, \& Mulholland, 1997;

80 Dickter \& Bartholow, 2007; Dickter \& Gyurovski, 2012). Using implicit behavioral tasks such as the dot-probe paradigm, researchers have demonstrated that perceivers allocate differential attention to outgroup versus in-group members (Brosch \& Van 5 Bavel, 2012; Trawalter, Todd, Baird, \& Richeson, 2008), whereas others have not (Dickter, Gagnon, Gyurovski, \& Brewington, 2014; Donders, Correll, \& Wittenbrink, 2008) susting that multiple isms may be responsible for differences in implicit attention to social groups. While some research suggests that attentional bias to out-group relative to ingroup faces is moderated by the degree of threat associated with the out-group (Donders et al., 2008), additional factors such as the degree to which perceivers are familiar with the out-group (Dickter et al., 2014) may also serve as moderators.

Although informative in understanding attentional processes, reaction time-based measures such as the dot-probe task are limited when examining the cogni-

100 tive processing of social groups. First, they are dependent on the speed of motor processes and task requirements (Ito \& Cacioppo, 2000). Second, they may be affected by cognitive control processes and thus may not be ideal when investigating responses to groups about which there may be concerns about social presentation (e.g., not wanting to appear prejudiced). An alternative approach that does not suffer from these limitations involves using psychophysiological measures, which provide a multifaceted view of the underlying neural events associated with the social categorization process. Event-related brain potentials (ERPs) in particular provide an ideal measure of implicit attention during social categorization due to their high temporal resolution. Additionally, because they are independent of the conscious control of the participant (Ito, Thompson, \& Cacioppo, 2004), they are particularly well-suited to examine responses to stimuli to which individuals, may be motivated to appear non-prejudiced or to inhibit negative responses to derogated social groups.

ERP research examining the categorization of social groups has demonstrated that early attention is directed differentially to in-group and out-group members; much of this research has focused on attention to race (e.g., Bartholow \& Dickter, 2008; Dickter \& Bartholow, 2007; Ito \& Bartholow, 2009; Ito et al., 2004; Ito \& Urland, 2003, 2005). There are several ERP components of interest when measuring early implicit attention to stimuli, namely the N1, P2, N2 $\_$and the P3/LPP (i.e., late positive potential). Amplitudes for each of these components represent the degree to which participants are attending to a certain type of stimulus. The N1 component occurs approximately $120 \mathrm{~ms}$ post-stimulus and, although there are inconsistencies across studies of social categorization, some studies have demonstrated that the $\mathrm{N} 1$ is larger to racial out-group relative to in-group members (e.g., Ito \& Urland, 2003). The P2 component ( $\sim 180$ ms post-stimulus) is more reliable and is consistently larger to racial out-group than in-group faces (e.g., Dickter \& Bartholow, 2007; Ito \& Urland, 2003, 2005). N1 and P2 amplitudes are associated with early orientation to novel, less familiar targets (Ito \& Bartholow, 2009). After about 250 ms poststimulus, attention shifts, as reflected by greater amplitudes; to racial and non-racial in-group faces shown -in the N2 ERP component (Dickter \& Bartholow, 2007, 2010; Hehman, Stanley, Gaertner, \& Simons, 2011), which is typically seen distributed over the anterior scalp and is consistent with medial prefrontal cortex activation (Ito \& Bartholow, 2009). Attention shifts again in the P3/LPP component ( 400-800 ms post-stimulus), with greater attention to out-group relative to in-group faces (e.g., Dickter \& Bartholow, 2007). The LPP is linked to the locuscoeruleus norepinephrine system that processes stimuli- that are motivationally significant (Ito \& Bartholow, 2009). The LPP is thus associated with negative evaluative judgments, even when participants overtly respond positively (Cacioppo, Crites, 
Berntson, \& Coles, 1993; Crites, Cacioppo, Gardner, \& Berntson, 1995; Ito \& Cacioppo, 2000). The LPP is largest to negative stimuli when embedded within other-positive stimuli, providing a measure of how

165 negative the stimulus is evaluated-relative to the other presented stimuli. The LPP may be particularly useful-to serve as an index of implicit evaluative responses to individuals of differing social groups. One such evaluative response may be a disgust 170 response to members of derogated groups (e.g., homosexuals; Nussbaum, 2010).

ERP studies have revealed important information about understanding differential processing of social categories based on visually prominent features such as race. However, less is known about attentional and affective processing specific to less easily categorizable groups such as sexual orientation. In order to fill this gap in the literature, the current study sought to accomplish several goals. First, we wanted to examine 180 whether differential attentional capture for out-group relative to in-group targets occurs for sexual orientation during the early stages of person perception using the N1, P2, and N2 ERP components. Second, we assessed the neural evaluative responses to targets of Previous research has shown that racial faces are

190 differentially encoded as a function of out-group familiarity (Walker \& Hewstone, 2006; Walker \& Tanaka, 2003). In one recent behavioral study, relative implicit attentional allocation to racial out-group versus in-group members was moderated by the number 195 of close out-group friends participants reported having, such that those with more out-group friends showed less attentional differences between in-group and out-group faces (Dickter et al., 2014). These results are reminiscent of findings demonstrating that 200 as individuals become more familiar with out-groups, they express less implicit (Shook \& Fazio, 2008) and explicit (e.g., Brewer \& Miller, 1984; Pettigrew, 1998; Pettigrew \& Tropp, 2008) out-group bias, which is consistent with contact theory (Allport, 1954).

To accomplish these goals, heterosexual collegeage participants were presented with pictures of in-group heterosexual and out-group homosexual couples and were asked to rate the images for pleasantness (Meier, Robinson, Gaither, \& Heinert, 2006) AQ3 210 while their neural activity was recorded using EEG. We chose to examine couples rather than individuals as target stimuli because, although research shows that sexual orientation can be identified in faces at an accuracy rate higher than chance (Rule, Ambady,
Adams, \& Macrae, 2008; Tskhay, Feriozzo, \& Rule, 2013), we predicted that pictures of couples interacting with one another would more clearly communicate their sexual orientation. Secondly, images of couples rather than group labels or symbolic representations of sexuality were used because we expected that implicit reactions to abstract symbols would be weaker relative to those induced by images of homosexual and heterosexual couples embracing or kissing.

We hypothesized that participants would demonstrate attentional and evaluative biases in the N1, P2, $\mathrm{N} 2$, and LPP ERP components and in their behavioral responses toward out-group couples compared to ingroup couples. That is, we expected differences in neural processing and behavioral responses between straight and gay couples as well as between straight and lesbian couples. We also expected that participants' reported close contact with out-group individuals would moderate the neural out-group-in-group attentional biases specific to the $\mathrm{N} 1, \mathrm{P} 2$, and $\mathrm{N} 2$ components. Although little research has examined whether the LPP component is moderated by familiarity, behavioral research has demonstrated that familiarity with stimuli reduces negative behavioral evaluative responses

\section{METHOD}

\section{Participants}

Participants were 58 undergraduates ( 28 male) between the ages of 18 and 30 years $(M=19.6$ years, $S D=2.2)$ at a medium-size public liberal arts university in Virginia who participated either for monetary payment or for the partial fulfillment of a course requirement. All participants were right-handed, and none had history of major head injury including stroke or concussion. All procedures were approved by the College of William and Mary Protection of Human Subjects Committee, and a-written informed consent was obtained from each participant.

\section{Materials}

\section{Picture stimuli}

Seventy-five images of gay, lesbian, and heterosexual couples previously collected and used in a study by Cunningham, Forestell, and Dickter (2013) were different sexual orientations using the LPP compo- nent. A third goal was to explore whether familiarity served as a moderator of the neural processing of out- group homosexual and in-group heterosexual couples. toward these stimuli (Bornstein, 1989; Fechner, 1876). Thus, we hypothesized that like the other ERP compo- nents, the LPP component would also be moderated by familiarity with gay and lesbian couples.


used in the current study. The pictures were carefully matched across the three categories in terms of facial expressions, physical appearance, environment, posture/pose, and degree of emotional involvement.

265 Together, these pictures formed 25 sets of corresponding gay, lesbian, and straight images. Each set of pictures depicted the couples engaging in an intimate activity (e.g., kissing, hugging, gazing into each other's eyes, holding hands). The couples were matched in terms of attractiveness and were all White or of indistinguishable race in order to ensure that differences in responses between pictures were due to the sexual orientation represented rather than other factors. They were also modestly dressed and did not have any unusual features (e.g., unconventional hair styles or piercings). Differences in the images' color and brightness were controlled by making all of the pictures black and white. All images were cropped to show only faces and upper torso.

\section{Picture viewing and rating task}

Participants completed a picture-viewing and rating task designed to assess implicit levels of discomfort toward homosexuality (Meier et al., 2006) as well as an explicit measure of the pleasantness of the images. In this task, each of the 75 images of gay, lesbian, and heterosexual couples was randomly selected and presented one at a time in the center of a 17", LCD computer monitor using E-Prime software (Psychology Software Tools, Inc., Pittsburgh, PA,

290 USA). Participants were informed that the purpose of this task would be to rate the photos for use in future experiments. They were instructed to take as long as they needed to view each image to ensure an accurate rating and to press the spacebar when they were ready to rate each image. Upon pressing the spacebar, participants were asked to rate the pleasantness of the photo with a rating scale that ranged from 1 (very unpleasant) to 9 (very pleasant). After a rating was selected, a blank screen appeared for an intertrial interval of $500 \mathrm{~ms}$, before the next image was presented. The time between presentation of the image and pressing the spacebar served as a measure of viewing time $($ an implicit measure of the participants' comfort with the images, as defined by Meier 305 et al.,2006).

\section{Questionnaires}

In addition to completing a demographic questionnaire in which they indicated their gender, age, and sexual orientation on a scale from 1 (exclusively

310 heterosexual) to 7 (exclusively homosexual) with a midpoint label of "bisexual", participants also completed the following questionnaires to assess explicit attitudes toward homosexuality and their familiarity with sexual minorities (i.e., gays and lesbians).

Attitudes toward lesbians and gay men scale (ATLG; Herek, 1988). The short form of the ATLG was used to assess attitudes toward homosexual individuals. This scale consists of 10 items, with half assessing attitudes toward gay men and half assessing attitudes toward lesbian women. Participants reported the degree to which they agreed with statements such as "Homosexual behavior between two men is just wrong" and "Lesbians just can't fit into our society" using a 7-point scale from 1 (strongly disagree) to 7 (strongly agree). This scale has been shown to have adequate internal consistency $(\alpha=.97)$, and in the present study internal consistency was similar to that previously reported $(\alpha=.94)$. Responses were reverse-coded where necessary and summed, with higher scores indicating more negative attitudes toward, homosexuality.

Feelings thermometer task (Esses, Haddock, \& Zanna, 1993). In the feelings thermometer task, participants were asked to indicate their feelings toward gay men and lesbian women with a sliding scale from 0 (cold) to 100 (warm), with a neutral midpoint at 50 .

Familiarity with sexual minorities. To assess close contact with sexual minority group members, participants provided the initials of up to 20 close friends and then subsequently identified the sexual orientation of those individuals. This measure was previously used by Dickter et al. (2014) and Greenwald et al. (1998) to covertly identify close friendships with individuals of different social groups. Proportions were computed for the number of gay and lesbian friends by dividing these by the total number of friends.

Participants also completed Walker, Silvert, Hewstone, and Nobre's (2008) social contact measure $(\alpha=0.87$; modeled after Voci \& Hewstone, 2003) to assess individuating experiences with gay and lesbian individuals. This measure includes questions such as "How often do you spend time with gay friends at their place?" and "How often have you received advice from a gay person when you are having a personal problem?" Questions were answered separately for gay and lesbian groups. Participants indicated on a 5 -point scale how strongly they agreed with these three statements. Higher scores indicated more current individuating experiences with each group. 
Participants were also asked to estimate the proportion of sexual minority individuals they knew during their childhood (i.e., through high school).

\section{PROCEDURE}

365 Upon arriving to the laboratory, participants completed a consent form and were seated in an electrically shielded Faraday chamber approximately $70 \mathrm{~cm}$ from a computer monitor. Participants were asked to be as still as possible during the experiment in order to reduce the amount of extraneous noise in the EEG recordings. Participants were told that the computer task involved the presentation of a series of 75 trials, each composed of a picture. They were instructed to view the pictures and to rate the pleasantness of each by pressing the spacebar to terminate the image, at which point a subsequent screen would appear in which they made their rating. This procedure, which was used by Meier et al. (2006), measures the reaction time to press the spacebar, which is thought to reflect 380 avoidance of the images; i.e., faster reaction times indicate a greater degree of avoidance-for the stimulus. After completion of the EEG task, participants completed the-questionnaires. When finished, they were debriefed and-given credit for their participation 385 and dismissed. All participants completed the study within an hour.

\section{Electrophysiological recording and analysis}

EEG data were recorded using a DBPA-1 Sensorium

390 Bioamplifier (Sensorium Inc., Charlotte, VT) with an analog high-pass filter of $0.01 \mathrm{~Hz}$ and a low-pass filter of $500 \mathrm{~Hz}$ (four-pole Bessel). The EEG was recorded from $74 \mathrm{Ag}-\mathrm{AgCl}$ sintered electrodes in an electrode cap, placed using the expanded International 10-20

395 electrode placement system. All electrodes were referenced to the tip of the nose and the ground electrode was placed in the middle of the forehead, slightly above the eyebrows. Eye movement and blinking were recorded from bipolar electrodes placed on the 400 lateral canthi and peri-occular electrodes on the superior and inferior orbits, aligned with the pupils. Before data collection was initiated, all impedances were adjusted to within 0-20 k $\Omega_{\text {. }}$ EEG was recorded continuously throughout the computer task ${ }_{\curlywedge}$ and was analyzed offline using EMSE software (Source Signal Imaging, San Diego, CA). Data were undersampled at $500 \mathrm{~Hz}$. The data were corrected for eye movement artifacts, using independent component analysis (Jung et al., 2000). Individual trials with voltages outside $\mathrm{a}-100$ to $100 \mu \mathrm{V}$ range were excluded from analysis. All EEG data were filtered at low pass $20 \mathrm{~Hz}$ (Luck, 2005). The data were segmented between $200 \mathrm{~ms}$ prior to stimulus onset and $1000 \mathrm{~ms}$ post-stimulus onset. After baseline correction over the pre-stimulus interval, segmented data were averaged for each subject in each of the conditions.

Visual inspection of the grand average waveforms was used to quantify each ERP component. In particular, an electrode variable was included in a repeated-measures analysis of variance along with the conditions of interest. The electrodes that typically present the ERPs of interest in similar past research were examined, and the electrode yielding the highest amplitude for each component was chosen. The N1 component was largest at electrode $\mathrm{Fz}$ and was quantified as the largest positive voltage between 60 and $160 \mathrm{~ms}$ at electrode Fz. P2 was quantified as the largest positive voltage between 130 and $240 \mathrm{~ms}$ at electrode $\mathrm{Pz}$. The N2 component was quantified as the largest negative voltage between 160 and $300 \mathrm{~ms}$ at electrode Fz. Finally, the LPP component was quantified as the largest positive voltage from 400 to $850 \mathrm{~ms}$ at $\mathrm{Pz}$.

\section{RESULTS}

\section{Participant characteristics}

Of the 58 participants, 18 were excluded from analyses due to problems with data recording $(n=10)$, errors sending condition codes to recording computer $(n=3)$, excessive EEG artifacts $(n=3)$, because they were ill $(n=1)$ or because they had participated in a previous behavioral study that used the same stimuli $(n=1)$. An additional 4 participants were excluded who indicated that they were not exclusively heterosexual (i.e., their score on the sexual orientation scale was greater than $2 ; n=2$ ) or they were outliers in terms of their age (i.e., older than 27 years; $n=2$ ). The remaining 36 participants (17 males) were between the ages of 18 and 22 years $(M=19.08$ years, $S E=0.21$, and $67 \%$ reported their race as White, $8 \%$ Black, $22 \%$ Asian, 3\% as multiracial. Of these, $6 \%$ indicated that they were of Hispanic or Latino descent.

Overall scores on the ATLG scale were similar for men $(M=3.85, S E=0.40)$ and women $(M=5.14$, $S E=0.60), t(34)=1.75$, As. However, relative to women, men indicated that they had a higher proportion of gay friends $(M=0.06, S E=0.01$ vs. $M=0.02$, $S E=0.01), t(34)=3.29, p<.01$. No such gender 
differences were found for the proportion of lesbian friends reported by men and women $(M=0.01$, $S E=0.01$ vs. $M=0.01, S E=0.01)$.

\section{Behavioral results}

Data for all but one participant were recorded during the picture-viewing and rating task. In order to examine whether reaction times to and explicit ratings of the pictures differed as a function of couple type and participant gender, each dependent variable (i.e., reaction times and ratings) was subjected to two mixed analyses of variance with couple type (either gay or lesbian vs. straight) as the repeated measure. As can be seen in Figure 1, results revealed that participants dismissed pictures of gay couples more quickly $(M=2691.38 \mathrm{~ms}, S E=229.22)$ than straight couples $(M=3088.03 \mathrm{~ms}, S E=276.73), F(1,34)=19.51$,

$475 p<.001, \eta^{2}=.365$. There nas signifieant differ ence for reaction times between the lesbian $(M=2990.78 \mathrm{~ms}, S E=269.63)$ and straight couples. As for participants' ratings of the couples, Figure 1 demonstrates that ratings of gay couples were overall more negative $(M=4.83, S E=0.26)$ than straight couples $(M=6.18, S E=0.16), F(1,34)=20.83$, $p<.001, \eta^{2}=.380$. Additionally, for the gay-straight

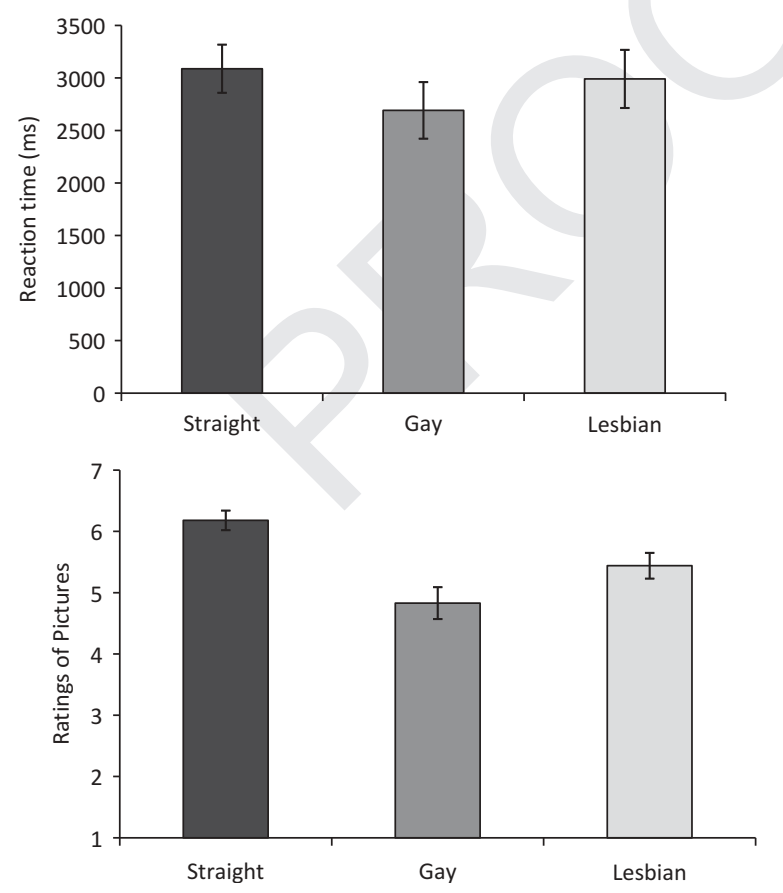

Figure 1. Reaction times to dismiss (top panel) and explicit ratings of (bottom panel) pictures of gay, lesbian, and straight couples. Error bars represent standard error of the mean. comparison, there was a significant couple type $x_{\lambda}$ participant gender interaction, $F(1,34)=7.44$, $p<0.01$. Simple main effects analyses revealed that men's ratings of the gay couples $(M=5.66$, $S E=0.37)$ were higher than those of women $(M=4.01, S E=0.37), F(1,34)=10.14, p<0.03$. For the straight-lesbian comparison, there was only a main effect of couple type. As shown in Figure 1, lesbian couples yielded lower ratings $(M=5.44$, $S E=.21)$ than straight couples regardless of participant gender, $F(1,34)=11.28, p<.002$. Participants' ATLG scores correlated significantly with their ratings of lesbian $(r=-.42, p<.01)_{\mathbf{1}}$ gay $(r=-.77, p<.01)$, but not straight $(r=0.11, p=0.53)$ couples.

\section{Psychophysiological results}

For the ERP components, preliminary analyses showed that there were no main effects of participant gender, nor did this factor interact with couple type, so analyses below are reported collapsing over gender. For each ERP component, the effect of couple type on ERP amplitude was assessed with dependent samples $t$-tests comparing amplitudes to straight couples first to gay couples and then to lesbian couples. Figures 2 and 3 depict the results of the analyses reported below.

N1. Results indicated that neither the difference in peak amplitude between straight and gay couples nor the difference between straight and lesbian couples was significant, all $p$ values $>.50$.

P2. This component was quantified for all but one participant. Results indicated that gay couples $(M=9.84, S E=1.25)$ yielded more positive peak amplitudes than straight couples $(M=8.30, S E=1.24)$, $t(35)=-2.11, p<.05$. However, there was no significant difference between lesbian $(M=9.49$, $S E=1.09)$ and straight couples, $t(35)=-1.62$, $p>.10$. These results suggest that there was greater early attention to the gay than to the straight couples.

N2. Results indicated that neither the peak amplitude between straight and gay couples nor the difference between straight and lesbian couples was significant, all $p$ values $>.40$.

LPP. Analyses demonstrated that gay couples $(M=11.10, S E=0.72)$ yielded significantly higher amplitudes than the straight couples $(M=4.88$, $S E=0.72), t(36)=-5.58, p<0.001$. Activation in response to the lesbian couples $(M=8.42, S E=1.07)$ was also larger than that to the straight couples, $t(36)=-3.54, p<.01$. These findings suggest that both-the gay couples and the lesbian couples may have been more motivationally significant for participants than the straight couples. 

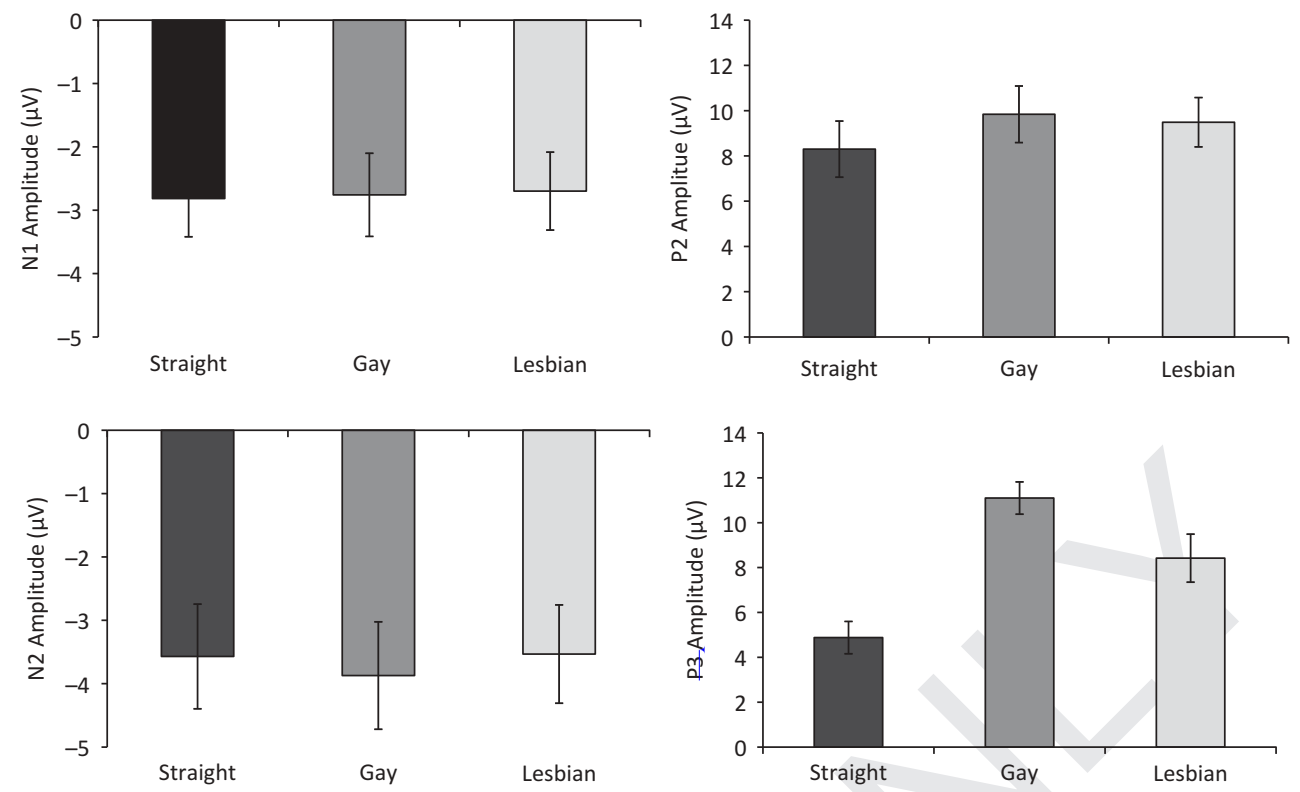

Figure 2. ERP amplitudes in response to pictures of straight, gay, and lesbian couples. The N1 and N2 ERPs are plotted at Fz. The P2 and LPP ERPs are plotted at Pz. Error bars represent standard errors. Note differences in $y$-axis range for positive and negative components.

\section{Relationships among variables}

535 In order to examine the relationships among variables, correlational analyses were conducted. Difference scores for RTs and ratings of the pictures were calculated by subtracting scores for lesbian and gay couples from those for straight couples. As a result, positive difference scores indicated a bias against homosexual couples relative to heterosexual couples. Results of these analyses revealed that RT biases were not correlated with ATLG, feelings thermometers, or any of the familiarity measures. However, rating biases for straight-gay couples were correlated with ATLG scores, $r=.75, p<.001$. Straight-lesbian rating biases were also correlated with ATLG scores, $r=.51$, $p<.002$. Both the straight-gay rating difference and the straight-lesbian rating difference were correlated 550 with contact with homosexuals, $r=-.61, p<.001$, and $r=-.36, p<.04$, respectively. Straight-gay ratings were negatively correlated with the gay feeling thermometer measure, $r=-.58, p<.001$, as well as social contact with gay people, $r=-.44, p<.008$, and individuating experiences with gay men. The straightlesbian rating difference score was correlated with social contact with lesbians, $r=-.34, p<.05$.

For each ERP component, two difference scores were calculated: one between peak amplitudes to the 560 straight and lesbian couples and another between peak amplitudes to the straight and gay couples. For both of these calculations, amplitudes to homosexual couples were subtracted from straight couples. This bias score was thus an indication of relative attention for the heterosexual and homosexual couples such that larger difference scores indicated greater bias between the two types of couples. Correlational analyses were then conducted between each component and RT, rating bias, percent childhood sexual minority experience, individuating experiences with gay/lesbian individuals, proportion of sexual minority friends, ATLG, and the feeling thermometers. Only significant or marginally significant correlations are reported below.

N1. There were no significant correlations between straight-gay difference score and any of the variables. There was a significant negative correlation between the straight-lesbian difference score for the $\mathrm{N} 1 \mathrm{com}$ ponent and individuating experiences with lesbians, $r(36)=-.35, p<.04$. Marginal correlations were found between N1 amplitude and the proportion of sexual minority friends, $r(36)=-.31, p<.07$, and the percent of childhood experiences with sexual minorities, $r(36)=-.29, p<.09$. These results demonstrate that those with a higher proportion of current sexual minority friends and peers and more contact with lesbians have smaller differences in N1 amplitude to straight, versus lesbian couples (i.e., a smaller bias).

P2. No significant correlations were found for straight-gay difference scores with any variable. For straight-lesbian difference scores, there was a significant correlation with the proportion of sexual minority friends participants currently have, $r(36)=-\bar{\lambda} .42$, 

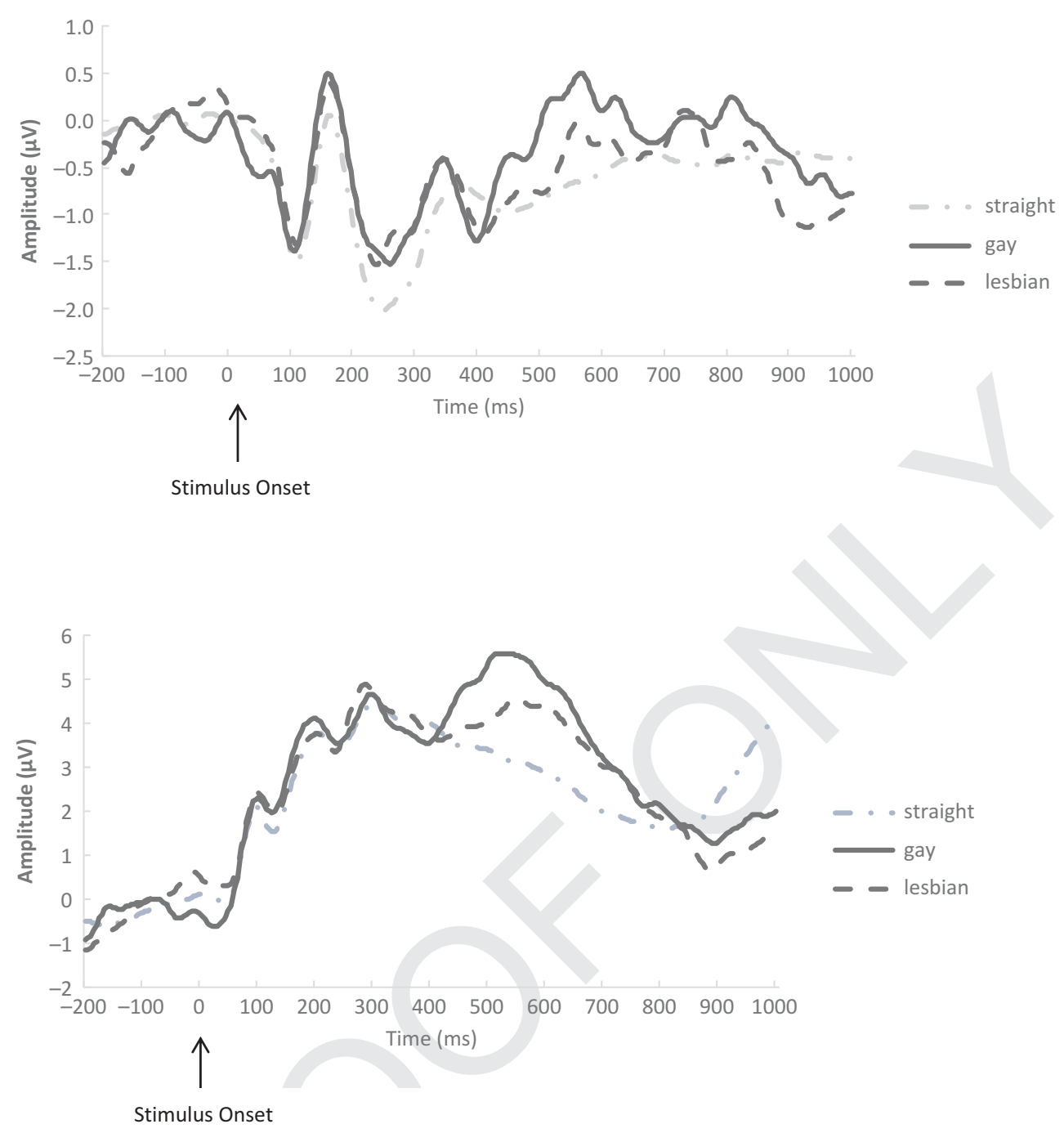

Figure 3. ERP amplitudes in response to pictures of straight, gay, and lesbian couples. The top waveform is plotted at electrode FZ. The bottom waveform is plotted at electrode PZ.

$p<0.02$, revealing that the greater the proportion of friends, the less ERP bias.

N2. No significant correlations were found between the bias scores for the N2 component and any of the other variables.

LPP. No significant correlations were found between the bias scored for the P3/LPP component

\section{DISCUSSION}

This study is the first to examine heterosexual individuals' neural processing of pictures of in-group straight and out-group gay and lesbian couples. This

study demonstrates that, similar to work on racial categorization, early neural attention in the P2 and later neural evaluative responses in the LPP are enhanced to out-group compared to in-group couples based on sexual orientation. Moreover, the amount of bias demonstrated for lesbian versus straight couples in the early ERP components appears to be related to participants' reports of their familiarity with this outgroup. These findings were further supported by behavioral findings, in that participants were faster to dismiss images of gay relative to straight couples, and ratings were lower for gay and lesbian couples relative to straight couples. Similar to the neural results, further inspection of the rating bias scores revealed that they were related to participants' contact with 
620 gays and lesbians and their feelings of warmth toward these groups.

Although there were no significant in-group-outgroup differences in the N1 ERP component, differences emerged in the P2 component. For the P2 component, larger amplitudes were observed to out-group gay relative to in-group straight couples, suggesting greater out-group attentional capture. These findings are in line with the-investigations of race, which have revealed that racial out-group targets elicit enhanced P2 amplitudes (e.g., Dickter \& Bartholow, 2007; Ito \& Urland, 2003). The current study suggests that gay couples, but not lesbian couples, are being processed as out-group members in a similar fashion to racial outgroups. The fact that individuals can encode contextual information, such as romantic involvement, from stimuli that are more ostensibly complex (i.e., pictures of two people) than a single face of a certain race, is consistent with previous work demonstrating that preferential attention to nuanced characteristics can occur

640 as early as $200 \mathrm{~ms}$ during social categorization. These results provide important insight into the social categorization that occurs as a result of perceived sexual orientation. Although not significant, visual inspection of the ERP plot from the present study reveals that ingroup couples yield somewhat larger N2 amplitudes than out-group couples. Research typically shows that racial in-group targets elicit larger N2 amplitudes than racial out-group targets.

Our results also revealed differences in processing 650 between out-group couples and in-group couples later in the LPP. Greater activation was observed to outgroup gay compared to in-group straight couples as well as to out-group lesbian compared to in-group straight couples. This pattern is consistent with previous work in the race literature showing greater amplitudes in LPP are associated with out-group processing (e.g., Dickter \& Bartholow, 2007). Because the LPP is associated with the processing of more motivationally significant stimuli and with negative 660 implicit evaluative judgments (Cacioppo et al., 1993; Crites et al., 1995; Ito \& Cacioppo, 2000), it may be the case that our findings reflect general negative affective responses to couples who represent a different sexual orientation from the perceivers.

It is possible that societal associations with homosexuality and disgust (Nussbaum, 2010) may play a role in the negative LPP evaluative response as well as the behavioral findings. Research has demonstrated a relationship between disgust and the evaluation of homosexuality (Cunningham et al., 2013; Dasgupta, DeSteno, Williams, \& Hunsinger, 2009; Inbar, Pizarro, \& Bloom, 2012; Inbar et al., 2009). While previous research demonstrated this relationship using behavioral measures, the current study demonstrates that negative affective responses and greater attention are seen during the neural processing of homosexual compared to heterosexual couples. Whether differences in LPP activation are moderated by disgust sensitivity or manipulations of disgust is a fruitful avenue for future work.

Although there were no differences in neural activity between the lesbian and straight couples in any of the early attentional ERP components, differences in activation to these couples were related to some of the familiarity measures. That is, smaller differences between the activation to lesbian and straight couples in the early ERP components N1 and P2 were found in those participants with more current relationships with lesbians and other sexual minority peers. These results suggest that although there was not a global difference in the processing of out-group lesbian versus in-group straight couples, processing varied as a function of participants' familiarity with these groups.

The relationship between activation and familiarity reported in this study is consistent with Allport's (1954) contact theory which suggests that meaningful intergroup contact with out-group members can change perceptions of out-group members. Previous examinations of contact theory demonstrate that close friendships that involve self-disclosure and intimacy over a sustained time period are particularly effective at reducing bias (e.g., Brewer \& Miller, 1984; Cook \& Seltiz, 1955; Pettigrew, 1998; Voci \& Hewstone, 2003). When considered in light of previous work, which demonstrates that close contact with out-group members is associated with smaller attentional differences between racial in-group and out-group members (Dickter et al., 2014), this work suggests that unfamiliarity with social groups may lead to differences in patterns of attention between the two groups. The mechanism responsible for the reduction in attentional differences is yet unclear. That is, close relationships with out-group members may reduce negative stereotypes, reduce the threat that is associated with outgroups, or reduce the novelty of out-group members themselves; work in our lab is currently examining mediating variables.

It is important to point out, however, that the correlations reported herein should be interpreted with caution, given that social contact was measured and not manipulated; the causal direction of this effect is unknown. Moreover, the current study was limited in that a relatively small sample size was used. Although this sample size is quite large compared to similar ERP studies, we should be careful in interpreting correlations between variables with a sample of this size. 
Because this is the first study to look at neural responses to couples representing different sexual orientations, more work is needed to determine the replicability of these effects. For example, future work could employ more sensitive measures of intergroup contact or employ stimuli depicting individuals whose social category is more ambiguous. Because studies have demonstrated that sexual orientation can be identified in faces at an accuracy rate higher than chance (Rule et al., 2008; Tskhay et al., 2013), it would be interesting to examine whether distinctions in neural processing occur in response to faces of homosexual and heterosexual individuals. Indeed, research is currently being conducted in our lab exploring this very question.

In summary, this work represents an important step in examining the neural processing of social in-groups and out-groups and opens the door to further investigations seeking to understand how homosexual couples are viewed by our society. Although a significant amount of social neuroscience research has focused on understanding early attention and evaluative processing of race, more work needs to be conducted to further understand the cognitive underpinnings involved in processing members of sexual minority groups. As prejudice against homosexuals is still prevalent in our society, understanding how attention to and evaluative processing of sexual minorities is important, as is the examination of other groups that are less easily identifiable.

Original manuscript received 24 April 2014 Revised manuscript accepted 11 December 2014 First published online $\mathrm{xx} \mathrm{xxx} \mathrm{xxxx}$

\section{REFERENCES}

Allport, G. W. (1954). The Nature of Prejudice. Reading, MA: Addison-Wesley.

765 Banse, R., Seise, J., \& Zerbes, N. (2001). Implicit attitudes towards homosexuality: Reliability, validity, and controllability of the IAT. Zeitschrift Für Experimentelle Psychologie, 48(2), 145-160. doi:10.1026//09493946.48.2.145

770 Bargh, J. A., Chen, M., \& Burrows, L. (1996). Automaticity of social behavior: Direct effects of trait construct and stereotype activation on action. Journal of Personality and Social Psychology, 71, 230-244. doi:10.1037/00223514.71.2.230

Bartholow, B. D., \& Dickter, C. L. (2008). A response conflict account of the effects of stereotypes on racial categorization. Social Cognition, 26(3), 314-332. doi:10.1521/soco.2008.26.3.314

Bettencourt, B., Dill, K. E., Greathouse, S. A., Charlton, K., \& Mulholland, A. (1997). Evaluations of ingroup and outgroup members: The role of category-based expectancy violation. Journal of Experimental Social Psychology, 33(3), 244-275. doi:10.1006/jesp.1996.1323

Bornstein, R. F. (1989). Exposure and affect: Overview and meta-analysis of research, 1968-1987. Psychological Bulletin, 106, 265-289. doi:10.1037/0033-2909.106.2.265

Brewer, M. (1988). A dual process model of impression formation. In T. Srull \& R. Wyer Jr. (Eds.), Advances in social cognition (Vol. 1, pp. 1-36). Hillsdale, NJ: Lawrence Erlbaum.

Brewer, M. B., \& Miller, N. (1984). Beyond the contact hypothesis: Theoretical perspectives on desegregation. In N. Miller \& M. B. Brewer (Eds.), Groups in contact: The psychology of desegregation (pp. 281-302). Orlando, FL: Academic Press.

Brosch, T., \& Van Bavel, J. J. (2012). The flexibility of emotional attention: Accessible social identities guide rapid attentional orienting. Cognition, 125, 309-316. doi:10.1016/j.cognition.2012.07.007

Cacioppo, J. T., Crites Jr., S. L., Berntson, G. G., \& Coles, M. G. H. (1993). If attitudes affect how stimuli are processed, should they not affect the event-related brain potential? Psychological Science, 4, 108-112. doi:10.1111/j.1467-9280.1993.tb00470.x

Cook, S. W., \& Seltiz, C. (1955). Some factors which influence the attitudinal outcome of personal contact. International Social Science Bulletin, 7, 51-58.

Correll, J., Park, B., Judd, C. M., \& Wittenbrink, B. (2002). The police officer's dilemma: Using ethnicity to disambiguate potentially threatening individuals. Journal of Personality and Social Psychology, 83(6), 1314-1329. doi:10.1037/0022-3514.83.6.1314

Crites, S. L., Cacioppo, J. T., Gardner, W. L., \& Berntson, G. G. (1995). Bioelectrical echoes from evaluative categorization: II. A late positive brain potential that varies as a function of attitude registration rather than attitude report. Journal of Personality and Social Psychology, 68 (6), 997-1013. doi:10.1037/0022-3514.68.6.997

Cunningham, E., Forestell, C. A., \& Dickter, C. L. (2013). Induced disgust affects implicit and explicit responses toward gay men and lesbians. European Journal of Social Psychology, 43(5), 362-369. doi:10.1002/ ejsp. 1945

Darley, J. M., \& Gross, P. H. (1983). A hypothesis-confirming bias in labeling effects. Journal of Personality and Social Psychology, 44, 20-33. doi:10.1037/00223514.44.1.20

Basgupta, N. (2004). Implicit ingroup favoritism, outgroup favoritism, and their behavioral manifestations. Social Hustice Research, 17(2), 143-169. doi:10.1023/B: SORE.0000027407.70241.15

Dasgupta, N., DeSteno, D. A., Williams, L., \& Hunsinger, M. (2009). Fanning the flames of prejudice: The influence of specific incidental emotions on implicit prejudice. Emotion, 9, 585-591. doi:10.1037/a0015961

Dasgupta, N., MeGhee, D. E., Greenwald, A. G., \& Banaji, M. R. (2000). Autematic preference for White Amerieans: Eliminating the familiarity explanation. Journal of Experimental Social Psychology, 36(3), 316 328. doi:10.1006/jesp.1999.1418

Dasgupta, N., \& Rivera, L. M. (2006). From automatic antigay prejudice to behavior: The moderating role of conscious beliefs about gender and behavioral control. Journal of Personality and Social Psychology, 91(2), 268-280. doi:10.1037/0022-3514.91.2.268

\section{5}


Dickter, C. L., \& Bartholow, B. D. (2007). Racial ingroup and outgroup attention biases revealed by event-related brain potentials. Social Cognitive and Affective Neuroscience, 2(3), 189-198. doi:10.1093/scan/nsm012

Dickter, C. L., \& Bartholow, B. D. (2010). Ingroup categorization and response conflict: Interactive effects of target race, flanker compatibility, and infrequency on N2 amplitude. Psychophysiology, 47(3), 596-601. doi:10.1111/ j.1469-8986.2010.00963.x

855 Dickter, C. L., Gagnon, K. T., Gyurovski, I. I., \& Brewington, B. S. (2014). Close contact with racial outgroup members moderates attentional allocation towards outgroup versus ingroup faces. Group Processes and Intergroup Relations. doi:10.1177/1368430214527854.

860 Dickter, C. L., \& Gyurovski, I. I. (2012). The effects of expectancy violations on early attention to race in an impression formation paradigm. Social Neuroscience, 7 , 240-251. doi:10.1080/17470919.2011.609906

Donders, N. C., Correll, J., \& Wittenbrink, B. (2008) Danger stereotypes predict racially biased attentional allocation. Journal of Experimental Social Psychology, 44(5), 1328-1333. doi:10.1016/j.jesp.2008.04.002

Dovidio, J. F., \& Gaertner, S. L. (2000). Aversive racism and selection decisions: 1989 and 1999. Psychological Science, 11(4), 315-319. doi:10.1111/1467-9280.00262

Fechner, G. T. (1876). Vorschule der aesthetik. Leipzig: Breitkoff \& Hartel.

Fiske, S. T., \& Neuberg, S. L. (1990). A continuum of impression formation, from category-based to individuating processes: Influences of information and motivation on attention and interpretation. In M. P. Zanna (Ed.), Advances in experimental social psychology (Vol. 23, pp. 1-74). New York, NY: Academic Press. doi:10.1016/ S0065-2601(08)60317-2

880 Gabriel, U., Banse, R., \& Hug, F. (2007). Predicting private and public helping behaviour by implicit attitudes and the motivation to control prejudiced reactions. British Journal of Social Psychology, 46(2), 365-382. doi:10.1348/014466606X120400

Giner-Sorolla, R., García, M. T., \& Bargh, J. A. (1999). The automatic evaluation of pictures. Social Cognition, 17(1), 76-96.

Greenwald, A. G., McGhee, D. E., \& Schwartz, J. L. K. (1998). Measuring individual differences in implicit cognition: The implicit association test. Journal of Personality and Social Psychology, 74(6), 1464-1480. doi:10.1037/0022-3514.74.6.1464

Hehman, E., Stanley, E. M., Gaertner, S. L., \& Simons, R. F. (2011). Multiple group membership influences facerecognition: Recall and neurological evidence. Journal of Experimental Social Psychology, 47(6), 1262-1268. doi:10.1016/j.jesp.2011.05.014

Herek, G. M. (1988). Heterosexuals' attitudes toward lesbians and gay men: Correlates and gender differences. The Journal of Sex Research, 25(4), 451-477. doi:10.1080/00224498809551476

Inbar, Y., Pizarro, D. A., \& Bloom, P. (2012). Disgusting smells cause decreased liking of gay men. Emotion, 12, 23-27. doi:10.1037/a0023984

905 Inbar, Y., Pizarro, D. A., Knobe, J., \& Bloom, P. (2009). Disgust sensitivity predicts intuitive disapproval of gays. Emotion, 9(3), 435-439. doi:10.1037/a0015960
Ito, T. A., \& Bartholow, B. D. (2009). The neural correlates of race. Trends in Cognitive Sciences, 13(12), 524-531. doi:10.1016/j.tics.2009.10.002

Ito, T. A., \& Cacioppo, J. T. (2000). Electrophysiological evidence of implicit and explicit categorization processes. Journal of Experimental Social Psychology, 36, 660-676. doi:10.1006/jesp.2000.1430

Ito, T. A., Thompson, E., \& Cacioppo, J. T. (2004). Tracking the timecourse of social perception: The effects of racial cues on event-related brain potentials. Personality and Social Psychology Bulletin, 30(10), 1267-1280. doi:10.1177/0146167204264335

Ito, T. A., \& Urland, G. R. (2003). Race and gender on the brain: Electrocortical measures of attention to the race and gender of multiply categorizable individuals. Journal of Personality and Social Psychology, 85(4), 616-626. doi:10.1037/0022-3514.85.4.616

Ito, T. A., \& Urland, G. R. (2005). The influence of processing objectives on the perception of faces: An ERP study of race and gender perception. Cognitive, Affective, \& Behavioral Neuroscience, 5(1), 21-36. doi:10.3758/CABN.5.1.21

Jung, T.-P Makeig, S., Westerfield, M., Townsend, J., Courchesne, E., \& Sejnowski, T. J. (2000). Removal of eye activity artifacts from visual event-related potentials in normal and clinical subjects. Clinical Neurophysiology, 111(10), 1745-1758. doi:10.1016/ S1388-2457(00)00386-2

Jussim, L., Palumbo, P., Smith, A., \& Madon, S. (2000). Stigma and self-fulfilling prophecies. In T. Heatherton, R. Kleck, M. R. Hebl, \& J. G. Hull (Eds.), The social psychology of stigma (pp. 374-418). New York, NY: Guilford Press.

Luck, S. J. (2005). Ten simple rules for designing ERP experiments. In En pats handbook.

Macrae, C. N., Milne, A. B., \& Bodenhausen, G. V. (1994). Stereotypes as energy-saving devices: A peek inside the cognitive toolbox. Journal of Personality and Social Psychology, 66(1), 37-47. doi:10.1037/0022-3514.66.1.37

McConahay, J. B. (1986). Modern racism, ambivalence, and the modern racism scale. In J. F. Dovidio \& S. L. Gaertner (Eds.), Prejudice, discrimination, and racism (pp. 91-125). San Diego, CA: Academic Press.

Meier, B. P., Robinson, M. D., Gaither, G. A., \& Heinert, N. J. (2006). A secret attraction or defensive loathing? Homophobia, defense, and implicit cognition. Journal of Research in Personality, 40, 377-394. doi:10.1016/j. jrp.2005.01.007

Nussbaum, M. C. (2010). From disgust to humanity: Sexual orientation and constitutional law. Oxford University Press.

Payne, B. K. (2001). Prejudice and perception: The role of automatic and controlled processes in misperceiving a weapon. Journal of Personality and Social Psychology, 81(2), 181-192. doi:10.1037/0022-3514.81.2.181

Pettigrew, T. F. (1998). Intergroup contact theory. Annual Review of Psychology, 49, 65-85. doi:10.1146/annurev. psych.49.1.65

Pettigrew, T. F., \& Tropp, L. R. (2008). How does intergroup contact reduce prejudice? Meta-analytic tests of three mediators. European Journal of Social Psychology, 38(6), 922-934. doi:10.1002/ejsp.504 
970 Rowatt, W. C., Tsang, J.-A., Kelly, J., LaMartina, B., Mccullers, M., \& McKinley, A. (2006). Associations between religious personality dimensions and implicit homosexual prejudice. Journal for the Scientific Study of Religion, 45(3), 397-406. doi:10.1111/j.14685906.2006.00314.x

975

Rule, N. O., Ambady, N., Adams Jr, R. B., \& Macrae, C. (2008). Accuracy and awareness in the perception and categorization of male sexual orientation. Journal of Personality and Social Psychology, 95(5), 1019-1028. doi:10.1037/a0013194

980

Sherrill, K., \& Yang, A. (2000). From outlaws to in-laws: Anti-gay attitudes thaw. Public Perspective, 11(1), 20-23.

Shook, N. J., \& Fazio, R. H. (2008). Interracial roommate relationships: An experimental field test of the contact hypothesis. Psychological Science, 19(7), 717-723. doi:10.1111/j.1467-9280.2008.02147.x

Steffens, M. C., \& Wagner, C. (2004). Attitudes toward lesbians, gay men, bisexual women, and bisexual men in Germany. Journal of Sex Research, 41(2), 137-149. doi:10.1080/00224490409552222

Trawalter, S., Todd, A. R., Baird, A. A., \& Richeson, J. A. (2008). Attending to threat: Race-based patterns of selective attention. Journal of Experimental Social Psychology, 44(5), 1322-1327. doi:10.1016/j. jesp.2008.03.006

Tskhay, K. O., Feriozzo, M. M., \& Rule, N. O. (2013). Facial features influence the categorization of female sexual orientation. Perception, 42, 1090-1094. doi: $10.1068 / \mathrm{p} 7575$

Voci, A., \& Hewstone, M. (2003). Intergroup contact and prejudice toward immigrants in Italy: The mediational role of anxiety and the moderational role of group salience. Group Processes \& Intergroup Relations, 6(1), 37-54. doi:10.1177/13684302030 06001011

Walker, P. M., \& Hewstone, M. (2006). A perceptual discrimination investigation of the own-race effect and intergroup experience. Applied Cognitive Psychology, 20(4), 461-475. doi:10.1002/acp.1191

Walker, P. M., \& Tanaka, J. W. (2003). An encoding advantage for own-race versus other-race faces. Perception, 32, 1117-1125. doi:10.1068/p5098

Yang, A. S. (1997). Trends: Attitudes toward homosexuality. The Public Opinion Quarterly, 61(3), 477-507. doi: $10.1086 / 297810$
1000 